\title{
Long-lasting effects of bentonite on properties of a sandy soil deprived of the humus layer**
}

\author{
Janusz Czaban ${ }^{1 *}$, Ewa Czyż $\dot{z}^{2,3}$, Grzegorz Siebielec ${ }^{2}$, and Jacek Niedźwiecki ${ }^{2}$ \\ ${ }^{1}$ Department of Agricultural Microbiology, ${ }^{2}$ Department of Soil Science, Erosion and Land Protection \\ Institute of Soil Science and Plant Cultivation - State Research Institute, Czartoryskich 8, 24-100 Puławy, Poland \\ ${ }^{3}$ Faculty of Biology and Agriculture, Rzeszów University, Aleja Rejtana 16c, 35-959 Rzeszów, Poland
}

Received February 21, 2013; accepted September 22, 2013

A b s t r a c t. Bentonite has been recognized as a very good material for the improvement of coarse textured soils. In microplot experiment, of a sandy soil deprived of the humus layer was enriched in 1973 with waste bentonite at the rates of $0,3,6$ and $12 \mathrm{~kg} \mathrm{~m}^{-2}$. Until 2002, the microplots were planted with different crops and regularly enriched with mineral and organic fertilizers. Since 2003, the microplots were left barren. In 2009, determinations of several features of the soils (in 5-30, 30-55 and 55-80 cm layers) showed that the historical amendment of the sandy soil with bentonite (especially its highest dose) ensured significantly higher contents of water, organic $\mathrm{C}$, clay, silt and a sand fraction with particle diameter $<0.1 \mathrm{~mm}$ in 5-30 $\mathrm{cm}$ layer. Proportions of non-dispersible clay in the total clay of bentonite soils in the two upper soil layers were significantly lower than those of the control soil. A significant increase in the penetrometer resistance was observed in 40-58 cm layers of the control soil and the soil with $3 \mathrm{~kg} \mathrm{~m}^{-2}$ bentonite amendment, contrary to the soils with two highest bentonite doses.

$\mathrm{K}$ e y w o r d s: sandy soil improvement, bentonite, particle size fractions, water content, SOM

\section{INTRODUCTION}

The coarse textured soils, due to their low content of clay, are infertile because they usually contain little humus, nutrients and water. Furthermore, many of these soils become acidified, because of their low buffering capacity (Croker et al., 2004; Filipek, 2001; Fotyma and Pietruch, 2001; Kátai et al., 2010b; Noble et al., 2000). Bentonite (BNT) a rock consisting predominantly of the clay mineral montmorillonite - has been recognized as a very good material for the improvement of coarse textured soils in

*Corresponding author e-mail: czaban@iung.pulawy.pl

**This paper was financed by 7FP project RECARE (Preventing and remediating degradation of soils in Europe through land care) No. 603498, 2013-2018. different parts of the world (Lazányi, 2005; Lhotský et al., 1970; Satje and Nelson, 2009; Yssad and Belkhodja, 2007). These studies, however, were of short term character. Therefore, it was hard to learn long lasting effects of bentonite addition to soil.

Important information pertaining to the question can be obtained from a microplot experiment that was conducted for thirty seven years since 1973 at the Institute of Soil Science and Plant Cultivation in Puławy, Poland (51 $\left.{ }^{\circ} 24^{\prime} \mathrm{N}, 21^{\circ} 57^{\prime \prime} \mathrm{E}\right)$. During the first 10-years of the study (1973-1983), it was found that the bentonite addition stimulated the accumulation of organic $\mathrm{C}$ and total $\mathrm{N}$, as well as in microbiological activity and fertility of the soil. Lower BNT rates had proportionally smaller effects (Kobus and Paszkowski, 1985).

The aim of the work presented here was to check whether the bentonite amendments affected soil properties after thirty years of cropping and seven years of fallowing.

\section{MATERIAL AND METHODS}

The experiment was established in 1973 on a subsoil (after removing the humus layer to $25 \mathrm{~cm}$ depth) of an acidic sandy soil $\left(\mathrm{pH}_{\mathrm{H}_{2} \mathrm{O}}\right.$ 5.4), containing in the upper layer $4 \%$ of particles $<0.02 \mathrm{~mm}$ and $0.35 \%$ of organic carbon (OC). In what follows, this exposed subsoil will be called 'the basic soil' which contained only traces of OC. The upper $(0-30 \mathrm{~cm})$ layer of the basic soil was enriched with waste bentonite (BNT) at the rates of: $0,3,6$ and $12 \mathrm{~kg} \mathrm{~m}^{-2}$ (0-BNTS, 3-BNTS, 6-BNTS, 12-BNTS) and with NPK fertilizers at the amounts of 300:300:500 kg ha ${ }^{-1}$ (nitrogen as $\mathrm{NH}_{4} \mathrm{NO}_{3}$, phosphorus as superphosphate and potassium as $\mathrm{KCl}$,

C 2014 Institute of Agrophysics, Polish Academy of Sciences 
respectively). BNT added to the soil was in a powdered form with the size of particles (PRT) of $<0.71 \mathrm{~mm}$ after drying at $400^{\circ} \mathrm{C}$. BNT contained $1.66 \%$ of total potassium (and $0.39 \%$ of $\mathrm{K}$ soluble in $10 \% \mathrm{HCl}), 0.73 \%(0.60 \%)$ sodium, $4.95 \%$ $(4.26 \%)$ calcium and $1.22 \%(0.60 \%)$ magnesium. Its cation exchange capacity was equal to $26 \mathrm{cmol}(+) \mathrm{kg}^{-1}$. The microplot experiment consisted of sixteen plots $\left(0.8 \mathrm{~m}^{2}\right)$ with concrete walls ( $1 \mathrm{~m}$ diameter, $1 \mathrm{~m}$ depth), four replicates for each of four experimental combinations (Kobus, 1979, 1983; Kobus and Paszkowski, 1985).

In the first two years of the experiment, the plots were planted with white mustard and lupin in order to enrich the soil with the green manure. Subsequently (for twenty eight years until 2002) the microplots were planted with potatoes, various cereals (oat, rye, triticale, barley, wheat), alfalfa and sometimes white mustard as the second crop. During these thirty years, the soils were treated with mineral fertilizers and exogenous organic matter (before growing of potatoes the soils were fertilized with farmyard manure, after growing of cereals they were enriched with the residual straw, and after growing of mustard, alfalfa or lupin with the green manure). The $\mathrm{pH}$ of the control soil (CS) not amended with BNT had to be regulated by $\mathrm{CaCO}_{3}$ addition several times. In 1974, the soils were inoculated with Azotobacter chroococcum (Kobus and Paszkowski, 1985). Since 2003, the plots have been left in a bare fallow with no fertilization.

All plots were sampled in May 2009 from the following soil depths: 5-30, 30-55 and 55-80 cm. The uppermost layer $0-5 \mathrm{~cm}$ of the soils was removed because of intensive but irregular growth of algae on the surface. The samples were placed in air-tight containers for transport to the laboratory. At the laboratory the samples were stored at $4^{\circ} \mathrm{C}$ in hermetically sealed containers until required.

Soil particle size classes were determined by the hydrometer method (HM), modified by Casagrande and Prószyński, based on measurements of the density of soil suspensions during progressive sedimentation, supplemented with the sieve method to fractionate sand. The content of particle size classes (sand 2.0-0.05 mm, silt 0.05-0.002 mm, and clay $<0.002 \mathrm{~mm}$ ) is presented according to the FAO/USDA classification system.

According to Dexter and Czyż (2011) and Dexter et al. (2008), the soil clay content was partitioned between clay that is complexed with OC and clay that is not complexed. The non-complexed clay is more easily dispersed in water than clay that is complexed with OC. Dexter and Czyż (2011) and Dexter et al. (2008) defined complexed clay (CC) as $\mathrm{CC}=(\mathrm{nOC})$ if (nOC $<$ clay) else $\mathrm{CC}=$ clay, while non-complexed clay (NCC) in turn was defined as $\mathrm{NCC}=$ (clay-CC) if (clay-CC) $>0$ else NCC $=0$. Dexter et al. (2008) found that $1 \mathrm{~g}$ of $\mathrm{OC}$ is associated or complexed with $10 \mathrm{~g}$ of clay. Therefore, the amount of clay complexed by soil organic carbon (SOC) was calculated as SOC x 10.
The amount of total clay (TC) and readily-dispersible clay (RDC) in water were determined by a turbidimetric method (TM) which was adapted for Polish sandy soils using a standard dilution and shaking procedure (Czyż et al., 2010a; Dexter et al., 2011). The clay stability, presented as a proportion of stable clay was calculated as $1-(\mathrm{RDC} / \mathrm{TC})$ in normalized turbidity units (NTU $\mathrm{g}^{-1}$ ).

Gravimetric water content of the soils (SWC) was measured in the laboratory by weighing the soil samples before and after drying at $105^{\circ} \mathrm{C}$ in an oven for $48 \mathrm{~h}$ in three replicates. Additionally, annual means of the contents of water in 0-30 cm soil layers, determined during the period of 19731985 plus 1990, are presented. In the period of 1991-2008 this parameter was not measured.

Soil strength was measured as penetration resistance $(Q)$ with a model CP20 cone penetrometer (Agridry RIMIK Pty. Ltd., Toowoomba, Australia) (Dexter et al., 2007). The penetrometer electronically records the value of $Q$ at depth intervals of $2 \mathrm{~cm}$ up to $60 \mathrm{~cm}$ depth. The average values of $Q$ at 6-30 and 32-56 cm depth were calculated to find correlations with various soil variables determined in 5-30 and 30-55 cm layers.

Soil pH was measured with a glass electrode in a slurry of $10 \mathrm{~g}$ of soil and $25 \mathrm{~cm}^{3}$ of deionized water.

Soil organic carbon (SOC) content was determined by the modified Tiurin method in which OC was oxidized to $\mathrm{CO}_{2}$ by a mixture of potassium dichromate and sulphuric acid and excess of dichromate was back titrated with a solution of Mohr Salt.

For statistical evaluation, the obtained results were subjected to one-way analysis of variance (at $p=0.05$ and the means were separated with Tukey test with $\mathrm{p}=0.05$ level of significance. For estimation of the relationships, the simple Pearson correlation analysis was used. Together with correlation coefficients $(r)$, the level of probability (p) and number of observations $(n)$ are presented.

\section{RESULTS AND DISCUSSION}

At the end of experiment (after 37 years), the control soil (CS) in the 5-80 cm layer consisted of approx.:

$-95 \%$ of sand $(\mathrm{PRT}>0.5-9 \%$, PRT $=0.5-0.25-41 \%$, $\mathrm{PRT}=0.25-0.1-42 \%$ and $\mathrm{PRT}=0.1-0.05-3 \%$ ),

$-4 \%$ of silt,

$-1 \%$ of clay.

In comparison with $\mathrm{CS}$, the soils with BNT added (BNTSs) were significantly richer in a fraction with $\mathrm{PRT}<0.1$ in the 5-30 and 30-55 cm layers (Fig. 1) (Czaban et al., 2013). Furthermore, CS contained significantly less: both clay and silt than the soil with $12 \mathrm{~kg} \mathrm{~m}^{-2}$ of the bentonite added (12-BNTS) in the 5-30 cm layer (Figs 1 and 2); and sand with PRT $=0.1-0.05$ than all BNTSs in the $5-30$ and $30-55 \mathrm{~cm}$ layers (Fig. 1). Similarly, Yssad and Belkhodja (2007) found that bentonite mixed with seaside sand in a pot experiment significantly enriched the sand with clay, fine silt 
and fine sand. Suzuki et al. (2007) also reported that an addition of bentonite into the top $20 \mathrm{~cm}$ layer of sandy soil significantly increased in this layer the contents of both silt and clay after 4 years.

The differences between CS and BNTSs in the contents of silt and clay distinctly decreased in the deeper soil layers
(Figs 1 and 2). Similarly, the differences in the content of total clay (TC) determined by the turbidimetric method (TC-d-TM) between CS and BNTSs (especially the soil with $12 \mathrm{~kg} \mathrm{~m}^{-2}$ of the BNT dose) observed in the $5-30 \mathrm{~cm}$ soil layer were distinctly reduced in $30-55$ and $55-80 \mathrm{~cm}$ soil layers (Fig. 3). This observation suggests that the fine parts

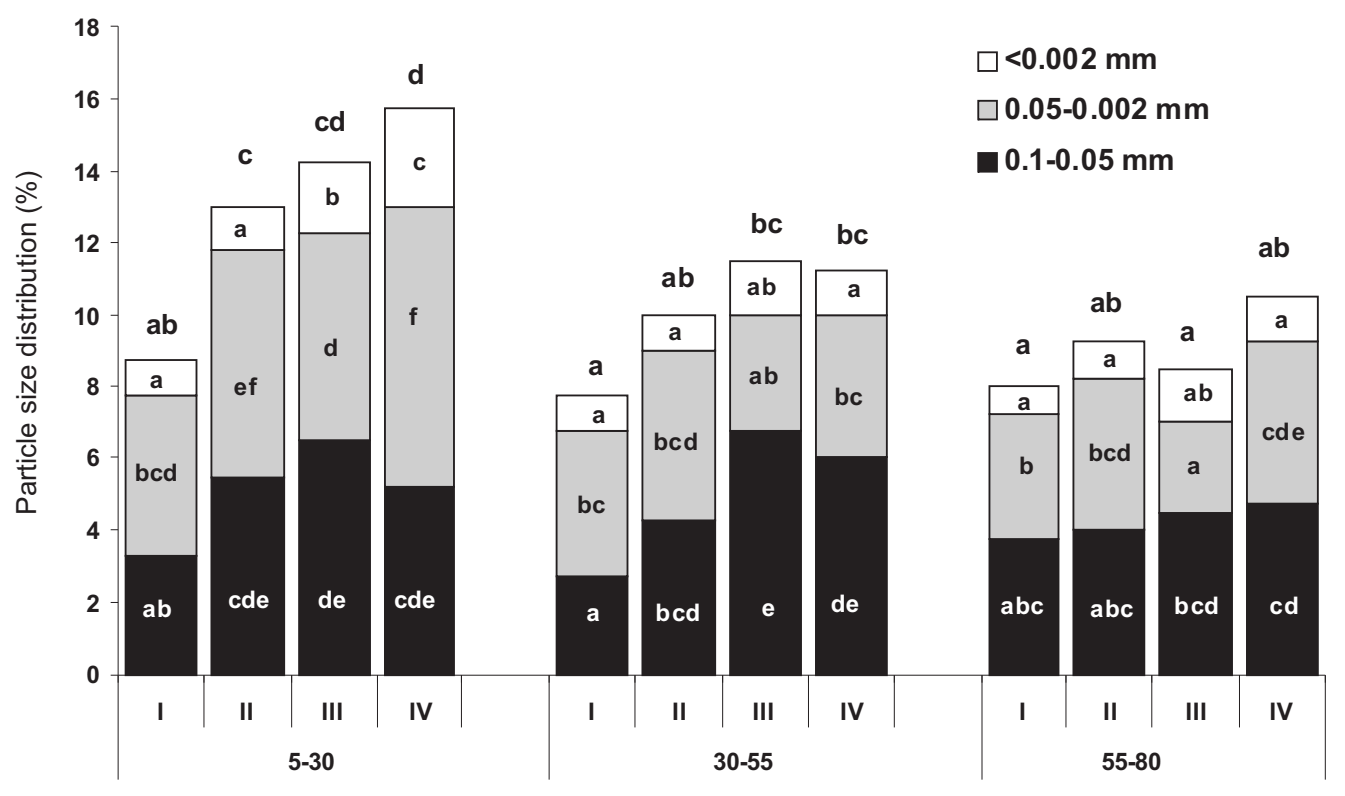

Soil layers $(\mathrm{cm})$

Fig. 1. Effect of the sandy soil amendment with: I -0 , II -3 , III -6 , and IV $-12 \mathrm{~kg} \mathrm{~m}^{-2}$ of the waste bentonite on contents of soil particle-size fractions $<0.1 \mathrm{~mm}$ (clay $-<0.002 \mathrm{~mm}$, silt $-0.05-0.002 \mathrm{~mm}$ and fine sand $-0.1-0.05 \mathrm{~mm}$ ) in $5-30,30-55$, and $55-80 \mathrm{~cm}$ soil layers. The values presented in the columns marked with different letters are statistically different at $\mathrm{p}=0.05$ (Czaban et al., 2013).

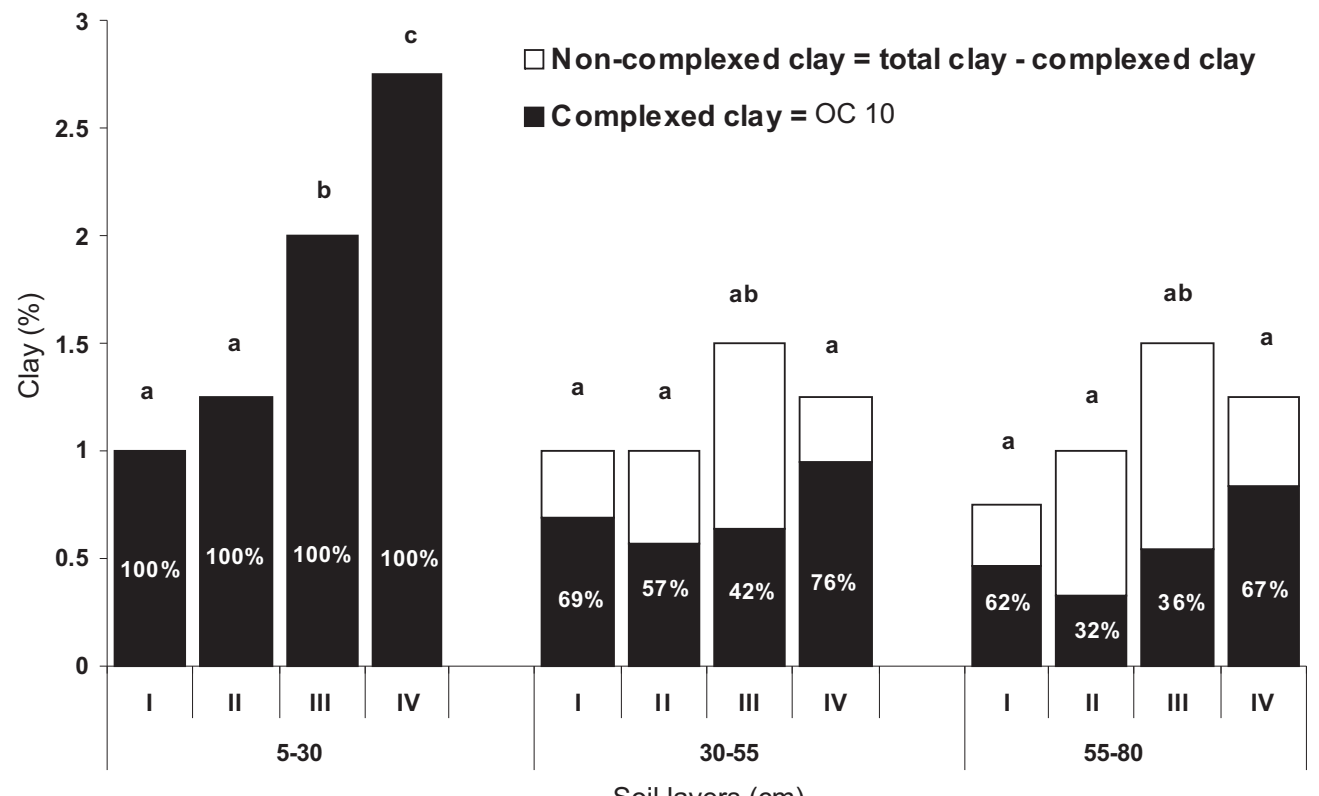

Soil layers $(\mathrm{cm})$

Fig. 2. Effect of the sandy soil amendment with: $\mathrm{I}-0$, II -3 , III -6 , and IV $-12 \mathrm{~kg} \mathrm{~m}^{-2}$ of the waste bentonite on contents of clay (and its fractions: complexed and non-complexed by SOC) determined by the hydrometer method in 5-30, 30-55, and 55-80 cm soil layers. On the black parts of the columns the percentage of complexed clay are presented. Other explanations as in Fig. 1. 
of BNT became partially transferred into deeper soil layers, but their biggest proportion stayed in the upper soil layer. Lhotský et al. (1970) also reported that migration of clay from bentonite in a sandy soil profile was not considerable. They found that bentonite, applied to $0-45 \mathrm{~cm}$ soil layer, increased the content of PRT $<0.002$ only to $60 \mathrm{~cm}$ depth after 4 years.

In contrast to clay and silt, the differences between CS and BNTSs in the contents of $<0.1 \mathrm{~mm}$ fraction of the sand were equal or even higher in $30-55 \mathrm{~cm}$ layers in comparison to the upper one (Fig. 1). Mažvila et al. (2008) have reported that if the soil is highly porous and contains a lot of vertical cracks and large pores, then heavy rain or shower may lead to mechanical migration of larger soil particles then clay and silt. It should be emphasized that such large pores were certainly present in the soils of our experiment where the plots with concrete walls were artificially filled with the basic soil. Therefore the vertical migration of the finest sand originated from BNT, which was less stabilized by soil organic matter than clay and silt, could occur. The finest sand fraction was not long ago was considered by Polish soil scientists as the coarsest fraction of silt. Skawina et al. (1981) reported that this fraction could be susceptible to water erosion and could migrate downward the soil profile.

The clay and silt contents in soils determined by the hydrometer method (HM) were higher in the 5-30 cm layer than in the deeper layers (Figs 1 and 2), contrary to the TC-d-TM contents which showed the opposite pattern (Fig. 3). Because of the fact that the biggest differences in TC-d-TM between the soil layers occurred in the case of CS, it is assumed that the clay originating from BNT was not responsible for the differences between the methods.

This supposition can be confirmed by the following reasoning. TC-d-TM was not correlated with content of any particle size fraction determined by HM nor with the contents of SOC and water. However, assuming that the content of TC-d-TM originating from the basic soil was on similar level in all treatments as in CS, subtractions of the TC-d-TM values of CS from the values of BNTSs should result in only the content of TC originating from BNT. After these subtractions TC-d-TM became significantly correlated with the contents of: PRT $<0.002 \quad(r=0.82$ at $\mathrm{p} \leq 0.01, n=12)$, PRT $=0.05-0.002(r=0.64$ at $\mathrm{p} \leq 0.05, n=12), \operatorname{SOC}(r=0.63$ at $\mathrm{p} \leq 0.05, n=12)$ and water $(r=0.85$ at $\mathrm{p} \leq 0.01, n=12)$.

The original TC-d-TM content (not changed by the subtractions) was correlated with $\mathrm{pH}(r=0.57$ at $\mathrm{p} \leq 0.01, n=48)$, but after subtractions of the TC-d-TM values of CS from the values of BNTSs, TC-d-TM content was not correlated with $\mathrm{pH}(r=0.16)$. Moreover, the correlation between the original TC-d-TM content (not changed by the subtractions) and $\mathrm{pH}$ was different in individual experimental series. This correlation was strong for CS and 3-BNTS ( $r=0.77$ and 0.84 at $\mathrm{p}<0.01, n=12)$, weaker for 6 -BNTS $(r=0.69$ at $\mathrm{p}<0.05$, $n=12)$, but in the case of the soil with the highest dose of BNT (12-BNTS), TC-d-TM was not correlated with the soil $\mathrm{pH}(r=-0.25$ and $n=12)$. All of these suggest that clay originating from the basic soil was directly/indirectly influenced by $\mathrm{pH}$ difference between the soil layers which disturbs the measurement of its content by TM (Fig. 4).

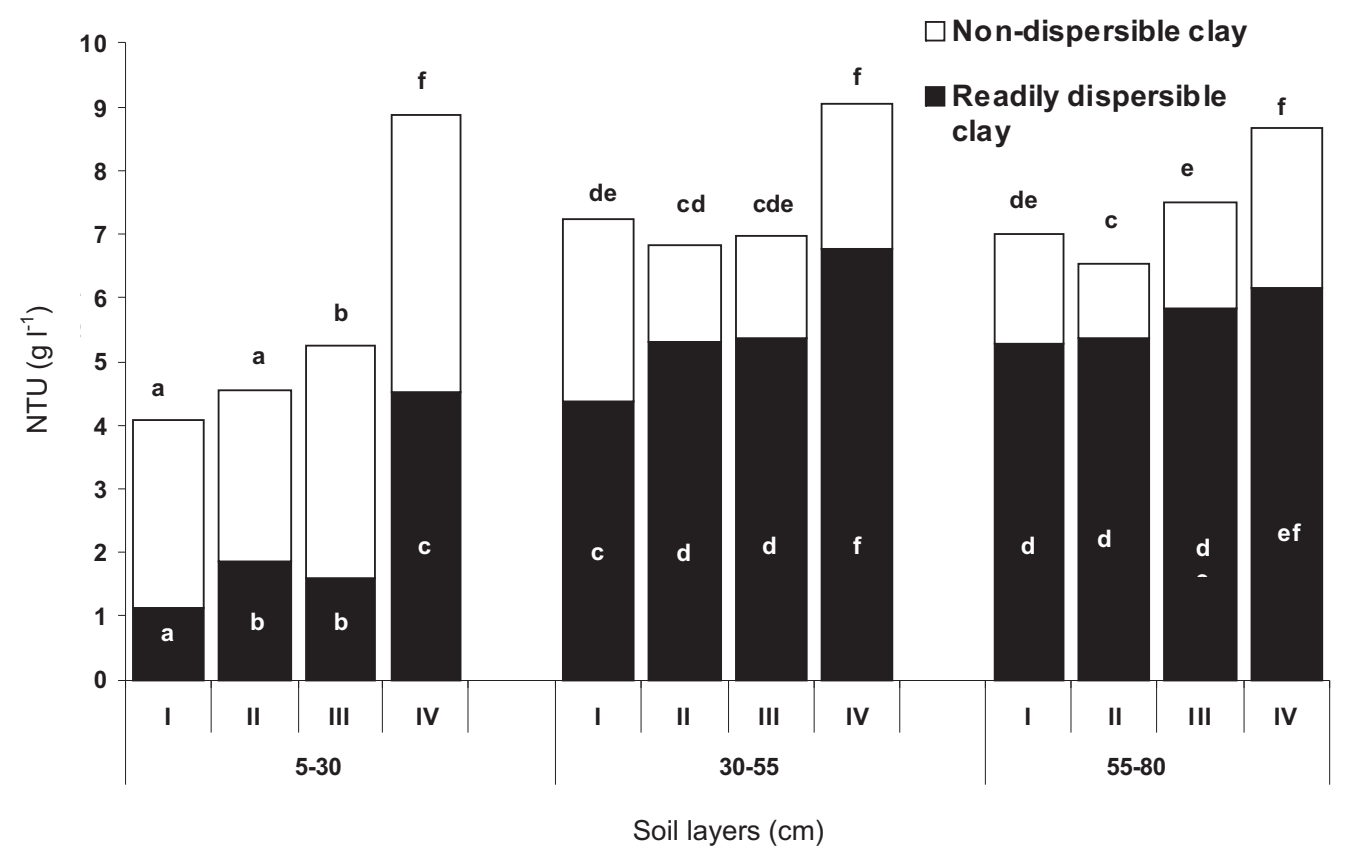

Fig. 3. Effect of the sandy soil amendment with: I-0, II -3, III -6, and IV $-12 \mathrm{~kg} \mathrm{~m}^{-2}$ of the waste bentonite on relative contents of total clay (TC) and readily-dispersed clay (RDC) determined by the turbidimetric method in 5-30, 30-55, and 55-80 cm soil layers. Other explanations as in Fig. 1. 


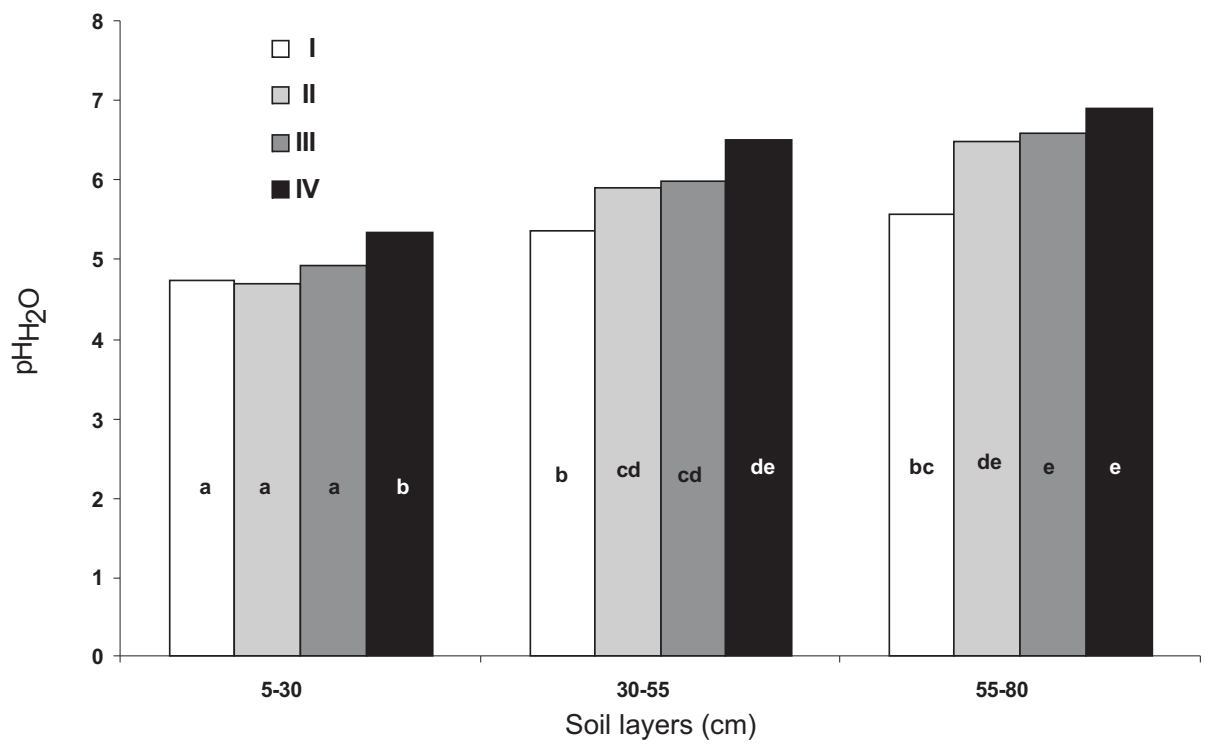

Fig. 4. Effect of the sandy soil amendment with: $\mathrm{I}-0$, II -3 , III -6 , and IV $-12 \mathrm{~kg} \mathrm{~m}^{-2}$ of the waste bentonite on soil $\mathrm{pH}$ in 5-30, 30-55, and 55-80 cm soil layers. Other explanations as in Fig. 1.

The readily dispersible clay (RDC) determined by TM followed a similar pattern to TC determined by the same method. The contents of this clay fraction were even higher in deeper soil layers in comparison to the upper one, and these increases were distinctly stronger in the case of CS than the soils with BNT added (Fig. 3).

The amounts of RDC were dependent on the TC-d-TM. Their contents were significantly inter-correlated $(r=0.82$ at $\mathrm{p} \leq 0.01, n=48$ ), and the contents of both RDC and TC-d-TM were negatively correlated with the clay stability $(r=-0.90$ and -0.53 for RDC and TC-d-TM, respectively, at $\mathrm{p}<0.01$, $n=48$ ). Such a significant correlation between the contents of RDC and TC in sandy soils was also determined by Czyż et al. (2010a). Therefore, the soil clay stability was negatively influenced not only by the content of RDC but also by the content of TC-d-TM. The strongest negative correlation between the clay stability and the TC-d-TM content $(r=-0.88$ and -0.87 at $\mathrm{p}<0.01, n=12$ ) and positive correlation between the contents of RDC and the TC-d-TM $(r=0.93$ at $\mathrm{p}<0.01$, $n=12$ ), were observed in the case of CS and 3-BNTS.

The clay stability was much lower in deeper soil layers than in the upper ones (Fig. 5). Czyż et al. (2010a) also reported that the amount of RDC in sandy soils was almost twice higher in sub-soils than in top-soil and that soil organic matter (SOM) had a significant effect on the dispersibility of clay particles. Their results show a negative correlation between the amount of RDC and SOM. Dexter and Czyż (2011) determined distinctly lower SOM content in a permanently fallowed soil than in cultivated soil cropped with various plants, that caused a distinct increase in the amount of clay non-complexed by SOM. Dexter and Czyż (2011) and Dexter et al. (2008) reported that SOM interacts with the clay particles to form a complex that is relatively stable in water, and that unit amount (by mass) of soil organic carbon
(SOC) forms a complex with 10 units of clay. In our studies, the content of SOC was also negatively correlated with the content of RDC ( $r=-0.65$ at $\mathrm{p} \leq 0.01, n=48)$, and strongly positively correlated with the clay stability $(r=0.79$ at $\mathrm{p} \leq 0.01$, $n=48$ ). The significant correlations (at $\mathrm{p}<0.01, n=12$ ) between the content of SOC and both RDC (from $r=-0.72$ to $r=-0.94$ ) and the clay stability (from $r=0.78$ to $r=0.95$ ) were found in the case of all the experimental series.

Clay stability was also strongly negatively correlated with soil $\mathrm{pH}(r=-0.77$ at $\mathrm{p} \leq 0.01, n=48)$, and the significant correlations (at $\mathrm{p} \leq 0.01, n=12$ ) were found for all BNT rates (from $r=-0.80$ to $r=-0.89$ ). It is difficult to conclude whether $\mathrm{pH}$ of the soils directly negatively affected the clay stability or this correlation can be random because in soils fallowed for such a long time, base substances migrated to deeper soil layers.

The higher contents of RDC in the two deeper soil layers were to a certain extent caused by low SOM content in these layers that was not high enough to complex all clay. This can be noticed after the subtraction of the calculated clay content complexed by SOC (ten times higher than SOC content) from the total content of clay $(<0.002 \mu \mathrm{m})$ determined by HM. The non-complexed clay (NCC) was present only in two lower soil layers (Fig. 2). The calculated percentage of complexed clay decreased with the depth of the soil in the case of all experimental series and it was correlated with the measured clay stability $(r=0.64$ at $\mathrm{p}<0.01, n=48)$.

Although CS had the lowest content of SOC among the soils (Fig. 6), the clay stability of BNTSs was significantly lower than that of CS in $5-30 \mathrm{~cm}$ and $30-55 \mathrm{~cm}$ soil layers (Fig. 5). Notwithstanding the fact that in:

- the 5-30 cm layer all clay is assumed to be complexed by SOM, because on the basis of data of Dexter and Czyż 


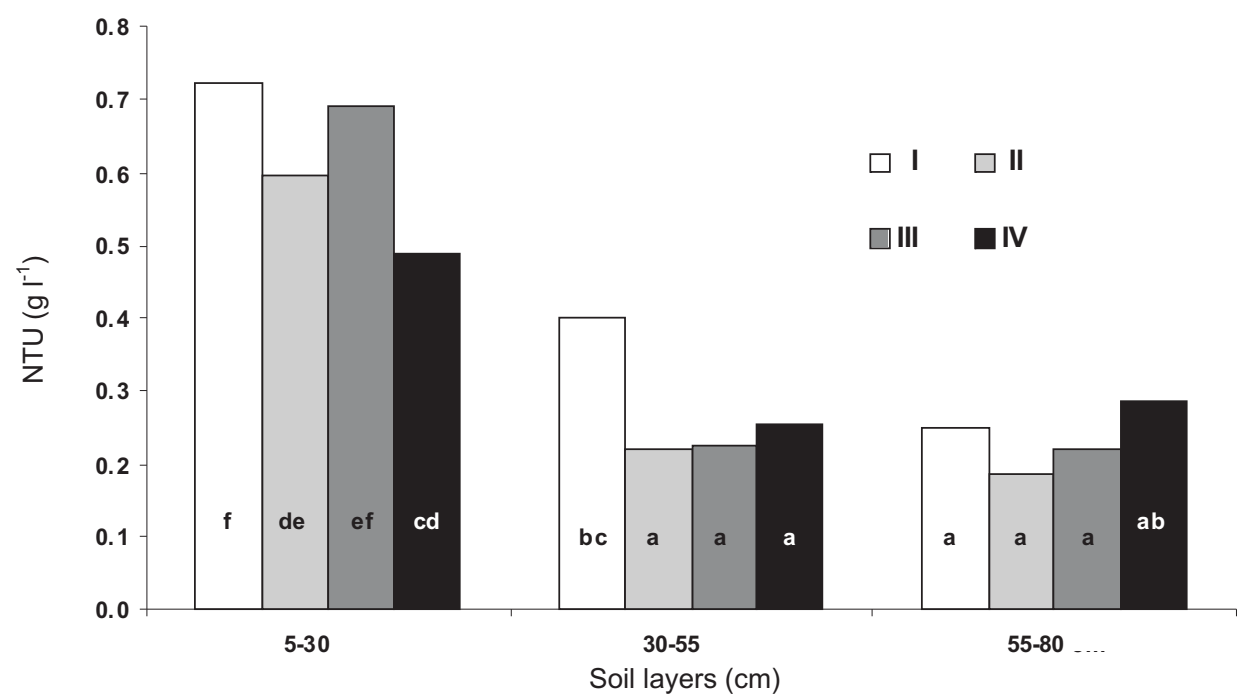

Fig. 5. Effect of the sandy soil amendment with: $\mathrm{I}-0$, II -3 , III -6 , and IV $-12 \mathrm{~kg} \mathrm{~m}^{-2}$ of the waste bentonite on clay stability in 5-30, 30-55, and 55-80 cm soil layers. Other explanations as in Fig. 1.

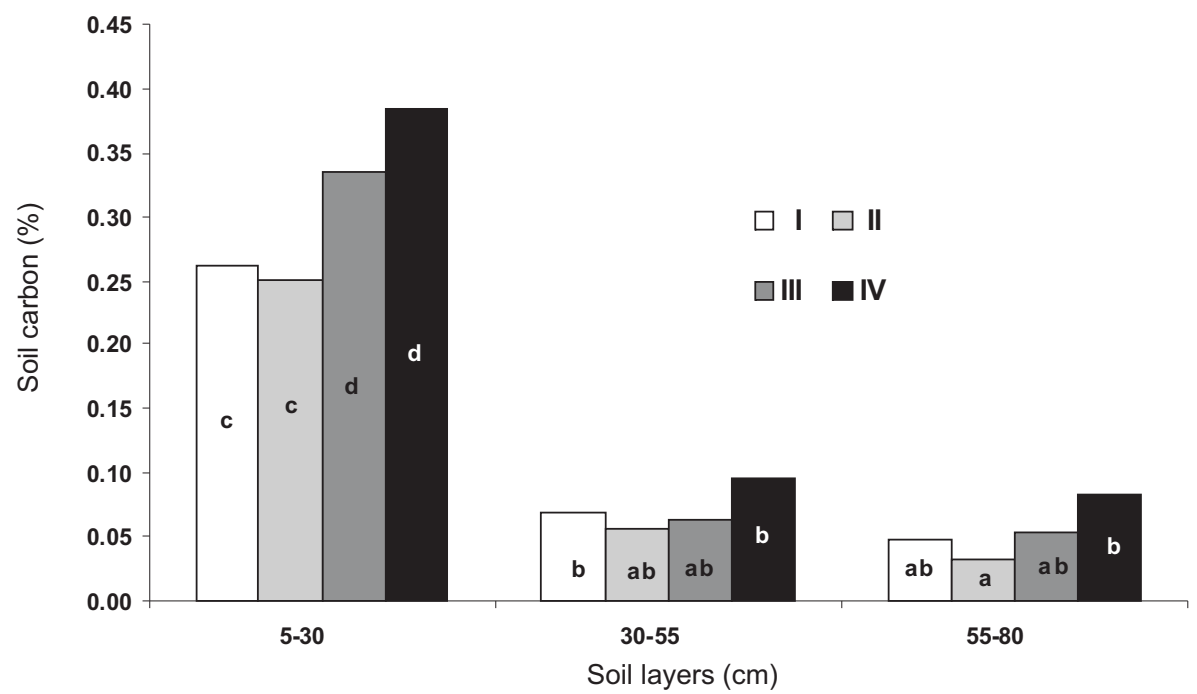

Fig. 6. Effect of the sandy soil amendment with: I -0 , II -3 , III -6 , and IV $-12 \mathrm{~kg} \mathrm{~m}^{-2}$ of the waste bentonite on soil carbon content in 5-30, 30-55, and 55-80 cm soil layers. Other explanations as in Fig. 1 (Czaban et al., 2013).

(2011) and Dexter et al. (2008) the content of SOC in this layer was high enough to make complexes with whole available clay;

- the $30-55 \mathrm{~cm}$ layer the percentage of complexed clay in CS was similar to that of the 12-BNTS (Fig. 2) the clay stability in CS was much higher than that of 12-BNTS (Fig. 5). However, the results presented in Fig. 2, showing that migration of clay was not substantial, suggest that the clay in BNTSs was stable.

It is difficult to explain the reason for the observed inconsistency. Two factors - much higher content of TC (Fig. 2) and soil water content (SWC) (Fig. 7) in 12-BNTS than those in CS - could be responsible to some extent for the dif- ference in the clay stability between CS and 12-BNTS. Czyż et al. (2010b) reported that the soils with greater TC content have a greater specific surface area and this can result in more clay being dispersed by low energy inputs. Montmorillonite, which was a major component of BNT, has a large specific surface area (Skawina et al., 1981), and it is most probable that clay originating from the basic soil was kaolinite, therefore its specific surface area should be expected to be much lower. Due to more intense negative charge and finer texture associated with montmorillonite clays, their stronger dispersion is possible than in the case of other types of clay (Rolfe at al., 1960). Czyż et al. (2010b) and Dexter et al. (2011) also reported that the proportion of clay dispersed 


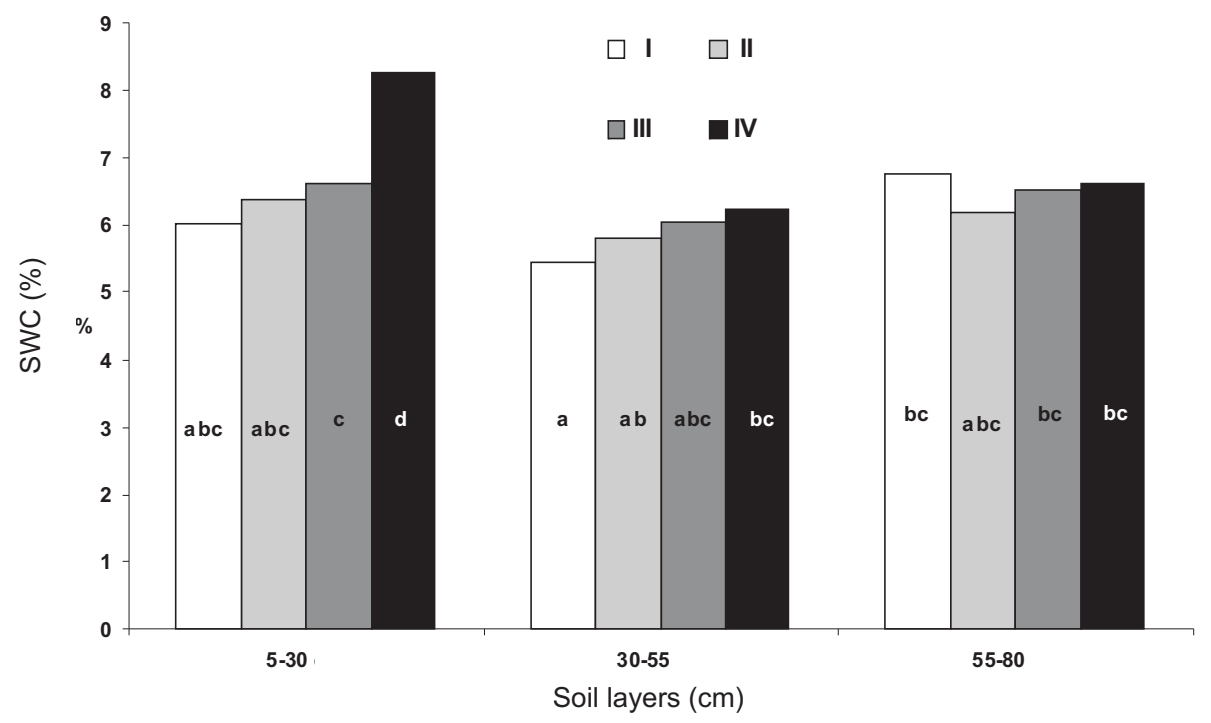

Fig. 7. Effect of the sandy soil amendment with: I- - , II -3 , III -6 , and IV $-12 \mathrm{~kg} \mathrm{~m}^{-2}$ of the waste bentonite on soil water content in 5-30, 30-55, and 55-80 cm soil layers in 2009. Other explanations as in Fig. 1.

was greater at larger values of SWC. The bentonite soils, especially the soil with the highest rate of the rock in the upper soil layer, of which the clay stability was much lower than that of CS, contained distinctly more water than CS (Fig. 7). It is not unlikely, that clay originating from BNT, present in BNTSs, needed different amounts of OC to be stabilized than clay present in CS. Schjonning et al. (2010) supposed that the mineralogical composition of clay was different among soils, which may compromise the Dexter idea of clay $/ \mathrm{OC}=10$ as a general threshold for clay saturation with OC. They concluded that their data support the concept of clay saturation with OC and differentiating soil content of clay in a complexed and non-complexed part, but did not unambiguously point out $\mathrm{n}=10$ as the clay/OC threshold.

The differences in $\mathrm{pH}$ between the soils were very small in the $5-30 \mathrm{~cm}$ soil layers, and only $\mathrm{pH}$ of the soil with the highest rate of BNT differed significantly from those of $\mathrm{CS}$, 3-BNTS and 6-BNTS. The soil pH increased significantly with increase of soil depth, especially in the case of BNTSs, therefore the differences in $\mathrm{pH}$ between CS and the BNTSs significantly rose with the increase in soil depth and the BNT dose (Fig. 4).

The upper layers of the soil enriched with the two highest rates of BNT had significantly higher SOC content than those of the two other treatments (Fig. 6). The SOC contents in the two lower soil layers were significantly lower from those in the $5-30 \mathrm{~cm}$ layer. In the deeper soil layers, the differences in SOC contents were not statistically proved (Fig. 6) (Czaban et al., 2013). The content of SOC was positively correlated with the content of PRT $<0.05 \quad(r=0.75$, at $\mathrm{p}<0.01, n=48$ ) which suggests that the added BNT (especially its highest dose) had an essential effect on OC content in the soils.
During the period of 1973-1990, soil water content (SWC) in the top $30 \mathrm{~cm}$ of soil was proportionally related to the amount of BNT added. The mean values of SWC in 6-BNTS and 12-BNTS significantly differ from that in CS at $\mathrm{p}<0.05$ (Fig. 8). The relation of the mean values to the doses of BNT shows the following linear equation:

$$
\% \mathrm{SWC}=0.172 x+4.32, \quad \mathrm{R}^{2}=0.99,
$$

where: $x$ - the dose of BNT added in $\mathrm{kg} \mathrm{m}^{-2}$.

On the day of sampling in 2009, SWCs were similar in all the studied soil layers of CS and the soils with the two lower BNT rates. Only in the case of 12-BNTS, SWC was significantly higher in the upper layer than in the deeper ones. Furthermore, SWC in 12-BNTS was significantly higher than those in CS in 5-30 cm and $30-55 \mathrm{~cm}$ layers, but the differences in SWC between the soils disappeared in the deepest soil layer (Fig. 7).

The average differences in SWC in the upper soil layer between CS and the BNTSs in two seven-year periods (1973-1979 and 1980-1985 plus 1990) and in 2009 were similar $(0.4,0.2$ and $0.3 \%$ in the case of 3 -BNTS; $1.0,1.0$ and $0.6 \%$ for 6 -BNTS; $2.0,2.0$ and $2.2 \%$ for 12 -BNTS). Moreover, the linear trend lines of SWC in all soil in the period of 1973-1985 plus 1990 are almost parallel to each other and to the $x$ axis (Fig. 9). This suggests that during the study period, the transport of soil particles, responsible for the water retention in the upper soil layers of BNTSs, downward through the soil profile was limited.

Soil water content was significantly (at $\mathrm{p}<0.01, n=48$ ) correlated with PRT $<0.05 \mathrm{~mm}$ and SOC $(r=0.55$ and 0.50 , respectively) but not with TC-d-TM and RDC. After subtraction of the CS values of TC-d-TM and RDC from the values of BNTSs, SWC became significantly (at $p<0.01$ ) 


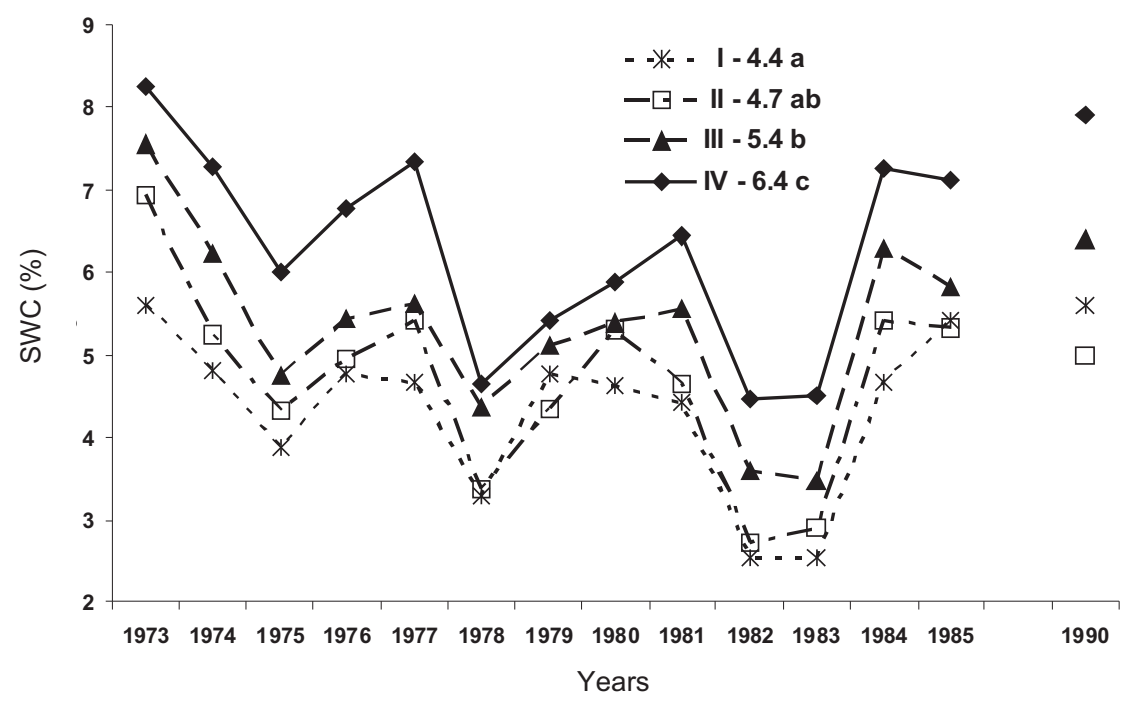

Fig. 8. Effect of the sandy soil amendment with: $\mathrm{I}-0$, II $-3, \mathrm{III}-6$, and IV $-12 \mathrm{~kg} \mathrm{~m}^{-2}$ of the waste bentonite on annual means of soil water content (SWC) in the 0-30 cm soil layers during the period 1973-1985 plus 1990. In the legend the means of SWC for the presented period are placed. Other explanations as in Fig. 1.

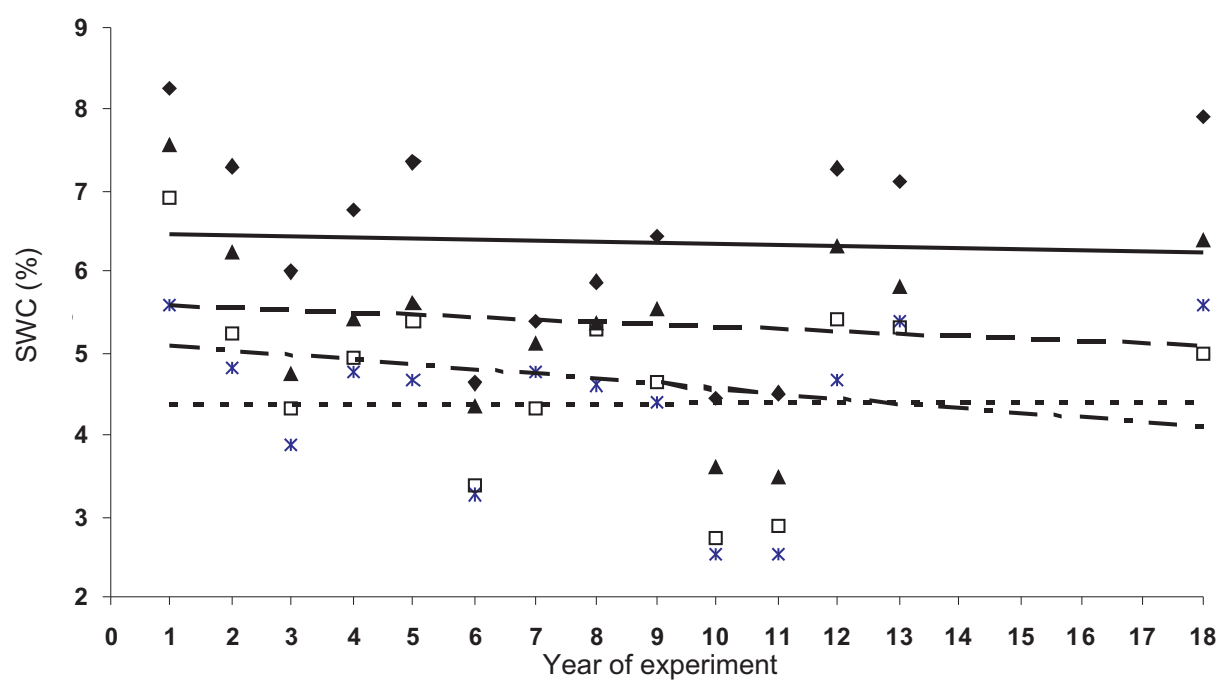

Fig. 9. Linear trend lines of SWC. Explanations as in Fig. 8.

correlated with both TC-d-TM and RDC ( $r=0.85$ and 0.71 , respectively, $n=12$ ). These observations mean that the BNT enrichment of the sandy soil was responsible for the higher SWC of the soils. An increase of water holding capacity of soils after bentonite amendments has been reported by other authors (Benkhelifa et al., 2007; Kátai et al., 2010a; Lhotský et al., 1970, Suganya and Sivasamy 2006; Suzuki et al., 2007; Satje and Nelson 2009).

Enrichment of sandy soils with bentonite increases their porosity and alters pore-size distribution (Suzuki et al., 2007; Satje and Nelson 2009). Lhotský et al. (1970) reported an increase in the proportion of pores $<0.3,0.3-3$, and 3-30 $\mu \mathrm{m}$ and a decrease of pores of 30-300 $\mu \mathrm{m}$ after soil amendment with bentonite. These changes increase water capillary rise (Lazányi, 2005). It is very interesting that Suzuki et al. (2007) and Satje and Nelson (2009) found that higher water holding capacity of sandy soils after their supplementation with bentonite significantly increased the field capacity (determined as the soil water content at $-10 \mathrm{kPa}$ ), although the permanent wilting point (determined at $-1500 \mathrm{kPa}$ ) remained relatively unchanged. Therefore, the bentonite treatments resulted in a remarkable increase in the available water content for crop growth.

The determination of penetration resistance $(Q)$ was chosen because it correlates with several soil properties of practical importance eg the draught force of tillage implements or the growth of plant roots (Dexter et al., 2007). Penetration resistance was similar in the case of all the soils 


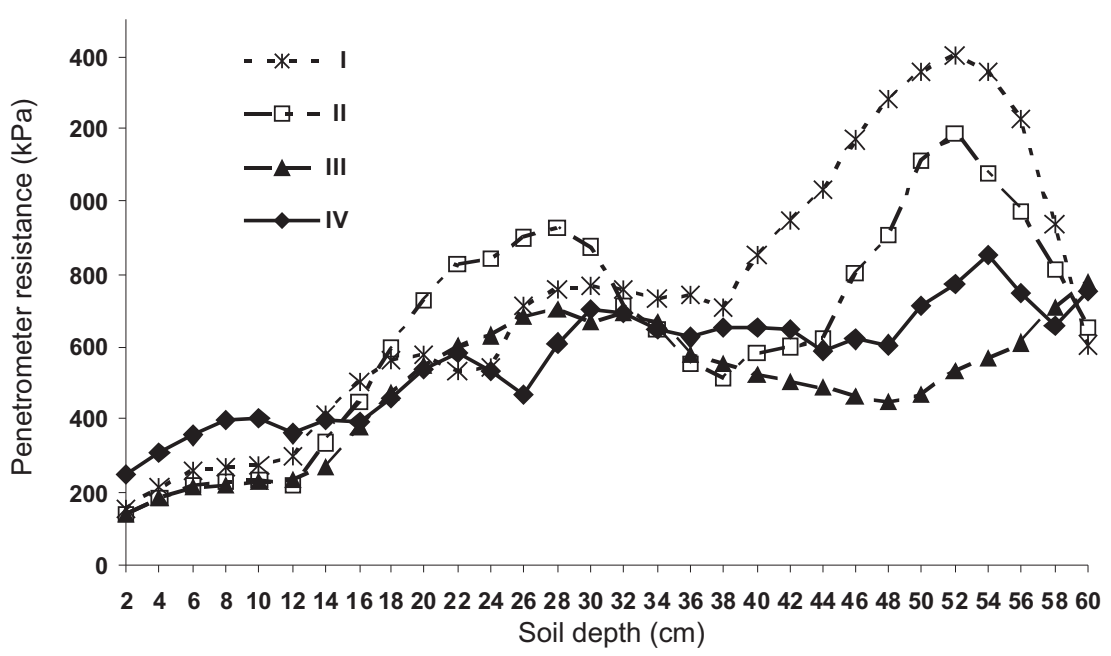

Fig. 10. Effect of the sandy soil amendment with: $\mathrm{I}-0$, II -3 , III -6 , and IV $-12 \mathrm{~kg} \mathrm{~m}^{-2}$ of the waste bentonite on penetrometer resistance of the soils.

to the depth of $38 \mathrm{~cm}$ excluding a slightly higher (but significant at $\mathrm{p}=0.05$ ) resistance of $12-\mathrm{BNTS}$ in the $2-10 \mathrm{~cm}$ layer and of 3-BNTS in the $20-30 \mathrm{~cm}$ layer. The biggest differences between the soils were found in $40-58 \mathrm{~cm}$ layers. At this depth CS and 3-BNTS showed significantly (at $\mathrm{p}=0.05$ ) higher $Q$ than that of 12 -BNTS and 6-BNTS (Fig. 10). Averaging the values of $Q$ in two upper soil layers (6-30 and 32-56 cm) enabled the calculation of correlations between $Q$ and other variables determined in the $5-30 \mathrm{~cm}$ and $30-55 \mathrm{~cm}$ soil layers. $Q$ was positively correlated at $\mathrm{p}<0.01 \quad(n=32)$ with the content of PRT=2-0.1 $(r=0.56)$ among which PRT $=0.25-0.1 \quad(r=0.41$, significant at $\mathrm{p}<0.025$ ) had the strongest effect. On the other hand $Q$ was negatively correlated (at $\mathrm{p}<0.01$ ) with the contents of SOC $(r=-0.64)$ and SWC $(r=-0.47)$ as well as with the content of PRT $<0.1(r=-0.56)$ among which not only clay and silt contents but also those of the finest sand (PRT $=0.1-0.05)$ most probably influenced $Q(r=-0.44$ and -0.46 for $\mathrm{PRT}<0.05$ and PRT $=0.1-0.05$, respectively). It suggests that the BNT was responsible for the difference in the soil strength as measured by $Q$ including the fraction of the fine sand $(\mathrm{PRT}=0.1-0.05 \mathrm{~mm}$ ) that migrated to the layer of $30-55 \mathrm{~cm}$ because in contrast to the finer soil fractions it should be less complexed with SOM.

It is difficult to explain why these two adjacent sand fractions PRT $=0.25-0.1$ and PRT $=0.1-0.05$ were so differently correlated with $Q$. Perhaps the different role of these two sand fractions in water retention in the soils was the reason of the difference. The finest sand fraction $(\mathrm{PRT}=$ 0.1-0.05), which not long ago was considered by Polish soil scientists as the coarsest fraction of silt, could be able (contrary to $\mathrm{PRT}=0.25-0.1$ ) to increase water retention in sandy soils (Skawina et al., 1981). The studies of Czaban et al. (2010) as well as other unpublished studies of Czaban on different Polish soils in a very long-term (since 1881) plot experiment where the soils were always cultivated by hand tillage, suggest that PRT $=0.1-0.05$ is closer to silt than to other sand fractions. They found, that this soil particle fraction, contrary to PRT $=0.25-0.1$, was positively correlated with: the volume of pores with a neck diameter 3-6 $\mu \mathrm{m}$ ( $r=0.75 v s$. to $r=-0.20$ for PRT $=0.25-0.1)$, which belonged to the soil microenvironment, often containing water and responsible for the retention of water easily available to plants); with the content of water available to plants $(r=0.63$ vs. $r=-0.17)$ and the number of hydrophilic fungi $(r=0.78$ $v s$. to $r=0.35$ ); but negatively with the volume of pores of $30-300 \mu \mathrm{m}(r=-0.67 v s$. to $r=0.20)$. The assumption that these two sand fractions originated from different sources $(\mathrm{PRT}=0.25-0.1$ from the basic soil and PRT $=0.1-0.05$ from BNT) can be also confirmed by their different chemical composition. PRT $=0.25-0.1$ was positively correlated with the content of total potassium $(r=0.44)$, contrary to the finest sand fraction $(r=-0.42)$, which, on the other hand was correlated with the content of total calcium $(r=0.42 \mathrm{vs}$. to $r=-0.18$ for $\mathrm{PRT}=0.25-0.1)$. All correlations were significant at $\mathrm{p}<0.05, n=32$ (results not presented).

\section{CONCLUSIONS}

1. After thirty seven years of a plot experiment, the amendment of a deprived of the humus layer sandy soil with the $12 \mathrm{~kg} \mathrm{~m}^{-2}$ of waste bentonite significantly enriched the soil with clay and silt only in its upper $5-30 \mathrm{~cm}$ layer. This suggests that the migration of the finer particles of bentonite into deeper soil layers (30-55 and 55-80 cm) was not substantial.

2 . The addition of two highest bentonite doses caused in 5-30 cm layer a significant increase in organic carbon content. In view of the fact that the soil organic carbon as well as silt and clay particles had remained in the upper layer of the bentonite soils, it was concluded that in that layer permanent organic-mineral complexes were formed. 
3. Besides of silt and clay, the bentonite added increased in the soil the content of the fraction of fine sand (0.1$0.05 \mathrm{~mm}$ ). In contrast to silt and clay, partial migration of the fine sand into the $30-55 \mathrm{~cm}$ layer occurred. Most likely, the sandy soil (composed mainly of particles of 0.5-0.1 mm) prepared in the plots, contained large pores that enabled the finest sand (less stabilized by soil organic matter than clay and silt) to migrate into the soil depth.

4. The enrichment of the soil in the fine particle fractions by the addition of $12 \mathrm{~kg} \mathrm{~m}^{-2}$ of bentonite caused a significant increase of soil water content in the $5-55 \mathrm{~cm}$ layer. The comparison of differences in soil water content in the upper $25 \mathrm{~cm}$ soil layers between the control soil and the bentonite soils in the 1973-1990 period (as well as in 5-30 cm layers in 2009) suggest that the upper soil layers were not becoming impoverished to a significant extent in the particles responsible for the water retention.

5. The amendment of the sandy soil with bentonite increased $\mathrm{pH}$ of the soil. The differences in $\mathrm{pH}$ between the control soil and the bentonite soils were significant in the deeper soil layers. It means that bentonite treatments diminished the acidification of the soil, especially in the deeper soil layers because greater amounts of base substances accumulated in deeper soil layers in the case of the bentonite soils than the control soil.

6 . The significant increase of the penetration resistance was found only in the $40-58 \mathrm{~cm}$ layers in control soil and soil with $3 \mathrm{~kg} \mathrm{~m}^{-2}$ of bentonite added.

\section{REFERENCES}

Benkhelifa M., Daoud Y., Benkhodja M., and Tessier D., 2007. Efficiency of furrow irigation on sandy soil amended with bentonite in arid and semi arid region. In: Water Saving in Mediterranean Agriculture and Future Research Needs (Eds N. Lamaddalena, C. Bogliotti, M. Todorovic, A. Scardigno). Proc. Int. Conf. Bari CIHEAM-IAMB, February 14-17, Valenzano, Italy.

Croker J., Poss R., Hartmann C., and Bhuthorndharaj S., 2004. Effects of recycled bentonite addition on soil properties, plant growth and nutrient uptake in a tropical sandy soil. Plant Soil, 267, 155-163.

Czaban J., Siebielec G., Czyż E., and Niedźwiecki J., 2013. Effects of bentonite addition on sandy soil chemistry in a long-term plot experiment (I); Effect on organic carbon and total nitrogen. Pol. J. Environ. Stud., 22, 1661-1667.

Czaban J., Wróblewska B., Niedźwiecki J., and Sułek A., 2010. Relationship between numbers of microbial communities in Polish agricultural soils and properties of these soils, paying special attention to xerophilic/xerotolerant fungi. Polish J. Environ. Studies, 19, 1171-1183.

Czyż E., Dexter A.R., and Gațe O.P., 2010a. Determination of soil stability in relation to ecological agriculture. In: Selected Problems of Soil Tillage Systems and Operations. (Eds P.F. Borowski, M. Klimkiewicz, M. Powałka), Warsaw University of Life Sciences, Poland.
Czyż E., Dexter A.R., and Gațe O.P., 2010b. Determination of the soil stability in relation to ecological agriculture. Proc. Int. Sci. Conf. Ecological Aspects of the Utilization of Vehicles and Agricultural Machinery, Selected Problems of Soil Tillage Systems and Operations. May 27, Warsaw, Poland.

Dexter A.R. and Czyż E., 2011. Soil crumbling during tillage as a function of soil organic matter content. Int. Agrophys., 25, 215-221.

Dexter A.R., Czyż E., and Gațe O.P., 2007. A method for prediction of soil penetration resistance. Soil Till. Res., 93, 412-419.

Dexter A.R., Richard G., Arrouays D., Czyż E.A., Jolivet C., and Duval O., 2008. Complexed organic matter controls soil physical properties. Geoderma, 144, 620-627.

Dexter A.R., Richard G., Czyż E.A., Davy J., Hardy M., and Duval O., 2011. Clay dispersion from soil as a function of antecedent water potential. Soil Sci. Soc. Am. J., 75, 444-255.

Filipek T., 2001. Natural and anthropogenic causes and effects of soil acidification. Fertilizers Fertilization, 3, 5-26.

Fotyma M. and Pietruch C., 2001. The actual status of soil reaction and demand for limestone in Poland. Fertilizers Fertilization, 3, 27-50.

Kátai J., Tállai M., Lazányi J., Lukácsné E.V., and Sándor Z., 2010a. Researches concerning the effect of bentonite on specific soil parameters and microbial characteristics of the carbon cycle. Natural Res. Sustainable Develop., 2010, 114-122.

Kátai J., Tállai M., Sándor Z., and Oláh Zsuposné Á., 2010b. Effect of bentonite and zeolite on some characteristics of acidic sandy soil and on the biomass of a test plant. Agrochemistry Soil Sci., 59, 165-174.

Kobus J., 1979. Effect of bentonite added to loose sandy soil together with excess of $\mathrm{P}$ and $\mathrm{K}$ on the yield and chemical composition of cereals. Polish J. Soil Sci., 12, 45-51.

Kobus J., 1983. Effect of the loose sandy soil fertilization with kaolinite and bentonite on the yield and the some mineral elements content of cereal crops (in Polish). Soil Sci. Annual, 34, 181-199.

Kobus J. and Paszkowski W., 1985. Effect of bentonite on biological activity and accumulation of carbon and nitrogen in a loose sandy soil in a long-term microplot experiment (in Polish). Pamiętnik Puławski, 84, 175-189.

Lazányi J., 2005. Effects of bentonite on the water budget of sandy soil. In: Culture Technology for Wheat and Corn. Symp. Int., July 7-8, Oradea, University of Oradea Press, Romania.

Lhotský J., Kremer J., Podlešáková E., Shrbená B., Skokan E., and Skokanová P., 1970. Theory of bentonite behaviour in soils. Scientific monographs. Res. Institute for Land Reclamation and Improvement Press, Zbraslav, Czech Republic.

Mažvila J., Vaičys M., and Beniušis R., 2008. Causes and consequences of the vertical migration of fine soil fractions. Agricultural Sci., 15, 36-41.

Noble A.D., Gillman G.P., and Ruaysoongnern S., 2000. A cation exchange index for assessing degradation of acid soil by further acidification under permanent agriculture in the tropics. Eur. J. Soil Sci., 51, 233-243. 
Rolfe B.N., Miller R.F., and McQueen I.S., 1960. Dispersion characteristics of montmorillonite, kaolinite, and hike clays in waters of varying quality, and their control with phosphate dispersants. Shorter Contributions to General Geology. Geological Survey Professional Paper, 334-G. US Government Printing Office, Washington, DC, USA.

Satje A. and Nelson P., 2009. Bentonite treatments can improve the nutrient and water holding capacity of sugarcane soils in the wet tropics. Proc. Australian Soc. Sugar Cane Technol., 31, 166-176.

Schjonning P., de Jonge L.W., Moldrup P., Christensen B.T., and Olesen J.E., 2010. Searching the critical soil organic carbon threshold for satisfactory tilth conditions - test of the Dexter clay: carbon hypothesis. Proc. 1st Int. Conf. Exploratory Workshop Soil Architecture and Physico-chemical
Functions (Eds L.W. de Jonge, P. Moldrup, A.L. Vendelboe). Aarhus University, Tjele, Denmark.

Skawina T., Kossowski J., and Stępniewski W., 1981. Physical properties of soils (in Polish). In: Soil Science (Eds B. Dobrzański, S. Zawadzki). PWRiL, Warsaw, Poland.

Suganya S. and Sivasamy R., 2006. Moisture retention and cation exchange capacity of sandy soil as influenced by soil additives. J. Applied Sci. Res., 2, 949-951.

Suzuki S., Noble A.D., Ruaysoongnern S., and Chinabut N., 2007. Improvement in water-holding capacity and structural stability of a sandy soil in northeast Thailand. Arid Land Res. Manag., 21, 37-49.

Yssad H.R. and Belkhodja M., 2007. The effect of bentonite on the physic chemical characteristics of sandy soils in Algeria. J. Applied Sci., 7, 2641- 2645. 